\title{
Antibacterial and toxicological evaluation of the ethanol leaf extract of Anthonotha macrophylla
}

\author{
Grace Akanimo Essiet ${ }^{1}$, Monday Udofa Anwankwo' ${ }^{1}$, Godwin Christian Akuodor ${ }^{2}$, Gloria Ahunna Ajoku ${ }^{3}$, Casimir \\ Chijioke Ofor ${ }^{4}$, Anthony Uchenna Megwas ${ }^{5}$, Daniel Ogbonna John Aja ${ }^{2}$ \\ ${ }^{1}$ Department of Pharmacology, Faculty of Basic Medical Sciences, College of Medical Sciences, University of Calabar, Calabar, Nigeria \\ ${ }^{2}$ Department of Pharmacology and Therapeutics, Faculty of Medicine, Ebonyi State University, Abakaliki, Nigeria \\ ${ }^{3}$ Department of Medicinal Chemistry and Quality Control, National Institute for Pharmaceutical Research and Development (NIPRD), Abuja, Nigeria. \\ ${ }^{4}$ Department of Pharmacology and Therapeutics, University of Nigeria, Enugu Campus, Nigeria \\ ${ }^{5}$ Department of Optometry, School of Health Technology, Federal University of Technology, Owerri, Nigeria
}

\section{A R T I C L E INF 0}

Article Type:

Original Article

\section{Article History:}

Received: 12 January 2019

Accepted: 8 March 2019

\section{Keywords:}

Anthonotha macrophylla

Leaf extract

Antibacterial activity

Toxicological assessment

\begin{abstract}
A B S T RA C T
Introduction: The leaves of Anthonotha macrophylla which are widely used in folkloric medicine in Africa were evaluated for antibacterial activity and its toxicological profile.

Methods: Antibacterial activities of the leaves against clinical strains of Staphylococcus aureus, Escherichia coli, Salmonella typhi, Klebsiella pneumonia, Streptococcus pyogenes and Bacillus subtilis were compared with cefoxitin. Toxicological profiles were determined following the administration of 100,200 and $400 \mathrm{mg} / \mathrm{kg}$ of the leaf extract and distilled water, as control, to male Albino rats for 28 days. Biochemical and hematological indices and body weights were determined and the vital organs were examined.

Results: The ethanol leaf extract of A. macrophylla demonstrated antibacterial activity against the pathogenic bacteria tested. Toxicological investigation of the leaf extract showed no significant alterations in hematological and biochemical indices, and the vital organs as well. The $\mathrm{LD}_{50}$ in rats was more than $5000 \mathrm{mg} / \mathrm{kg}$.

Conclusion: Findings suggest that the ethanol leaf extract of A. macrophylla possess good antimicrobial activity which supports the traditional use of this plant across Africa. The plant is also considered safe following oral exposure after 28 days.
\end{abstract}

Implication for health policy/practice/research/medical education:

Anthonotha macrophylla ethanol leaf extract significantly demonstrated broad-spectrum antibacterial activity and nontoxic effect. Hence, this plant can be considered as a candidate for bioassay-guided and isolation of compounds which could possibly be developed into new lead structures for drug development programs against diseases.

Please cite this paper as: Essiet GA, Anwankwo MU, Akuodor GC, Ajoku GA, Ofor CC, Megwas AU, Aja DOJ. Antibacterial and toxicological evaluation of the ethanol leaf extract of Anthonotha macrophylla. J Herbmed Pharmacol. 2019;8(3):205-211. doi: $10.15171 /$ jhp.2019.30.

\section{Introduction}

The use of plants for medicinal purposes is an age long practice which has given rise to a number of new therapeutic agents (1-3). Traditional medicine remains the mainstay of health care system especially in developing countries where orthodox medicines are regularly used. Medicinal plants are being employed globally for the treatment of different diseases which could not be properly managed with conventional agents (4). However, these plants are continually being evaluated for their bioconstituents and pharmacological activities. More so, researchers are making progressive efforts to determine the advantages of herbal medicines in modern science aimed at adopting efficient medical practice and overcoming the harmful ones (5).

Anthonotha macrophylla P. Beauv (family LeguminosaeCaesalpinioideae) is one of the plants used by the locals in Akwa Ibom and Cross River States, Nigeria to treat a number of health challenges. It is one of the species in the genus Anthonotha, a shrub of 4-20 m in height grown in the wild or uncultivated farmlands. Its vernacular names are 'nya' by the Ibibios and Efiks, 'ububa-iepa' by the Igbos and 'abara' by the Yorubas (6). The plant originated from Liberia but has spread to other parts of Tropical African countries including Cameroon, Gabon and Zaire in the West-Central; Nigeria and Ghana in the 
West; and Angola in the South. The leaves of the plant are particularly used in folkloric medicine with claims of its effectiveness in the treatment of pain, boils, malaria, worm infestation, gonorrhea, dysentery, yellow fever and diarrhoea. However, there is limited scientific evidence on most of such usage. The antimalarial activity of the leaf extract has been scientifically established (7). However, till date studies on antibacterial and toxicological profile of the ethanol leaf extract of $A$. macrophylla have not been reported. Hence, the present study evaluated the possible antibacterial potential of the plants' leaf extract and its safety in rats.

\section{Materials and Methods}

Collection and preparation of plant materials

The leaves of A. macrophylla were collected from a farmland in Ikot Ambang village in Ibiono Local Government Area of Akwa Ibom State, Nigeria during the months of February and March 2017. The leaves were authenticated in the Department of Botany, University of Calabar and a specimen with voucher number 736 was deposited in the herbarium of that department for future reference. The leaves were cleaned, air-dried on the surface of the laboratory bench and ground into coarse powder using a hand operated grain mill (Corona ${ }^{\circledR}$, Columbia).

Preparation of the extract

Five hundred grams of the leaf powder was extracted in ethanol using Soxhlet apparatus. The ethanol extract solution was dried on a water bath at a temperature of $45^{\circ} \mathrm{C}$ to give a yield of $21.02 \% \mathrm{w} / \mathrm{w}$ on dried weight basis. The extract was reconstituted in distilled water for use during the experiment.

Phytochemical analysis

The presence of bioactive constituents from the ethanol leaf extract of A. macrophylla was carried out using standard chemical methods $(8,9)$.

\section{Microbial strains}

Six clinical pathogenic bacteria (Escherichia coli, Klebsiella pneumonia, Bacillus subtilis, Streptococcus pyogenes, Staphylococcus aureus and Salmonella typhi) were used to evaluate the antibacterial activity of the ethanol leaf extract. All isolates were from the Department of Microbiology, University of Calabar Teaching Hospital, Calabar.

\section{Antimicrobial assay}

The antimicrobial activity of the ethanol extract was assayed using disc agar diffusion method of Akuodor et al (10). Before the assay, purity plates of required microbial isolates were isolated and biochemical tests carried out to confirm the identity of the organisms. Furthermore, discrete colonies of the fresh cultures from bacterial isolates were however mixed in $5 \mathrm{~mL}$ nutrient broth and incubated at $37^{\circ} \mathrm{C}$ for 24 hours. Broth cultures of $0.5 \mathrm{~mL}$ isolate containing $10^{5} \mathrm{cfu} / \mathrm{mL}$ of organism thoroughly reconstituted and emptied into sterile petri-dish together with $15 \mathrm{~mL}$ of Muller-Hinton agar was prepared to the manufacturer's instructions. The content was thoroughly mixed and allowed to solidify. Holes were bored in the plates with a standard sterile cork borer of $8 \mathrm{~mm}$ in diameter and the ethanol leaf extract reconstituted in distilled water at concentrations of 50, 100, 150, 200 and $250 \mu \mathrm{g} / \mathrm{mL}$, solvent blank and cefoxitin (standard antimicrobial drug) were applied in different wells in the culture plates. The studies were carried out in duplicate, the plates were kept for 2 hours for proper mixing of the extract which was then incubated at $37^{\circ} \mathrm{C}$ for 48 hours. The diameters of zones of inhibition were later measured against the organisms tested. Cefoxitin in concentration of $20 \mu \mathrm{g} / \mathrm{mL}$ was used as a standard drug and distilled water was used as control. The diameter of area of inhibition (antibacterial activity) was then compared with the standard drug and control.

Determination of minimum inhibitory concentration The method of Andrews (11) was used to determine the minimum inhibitory concentration (MIC) of $A$. macrophylla ethanol leaf extract. Six tubes (sterile) were arranged in a rack and $0.5 \mathrm{~mL}$ nutrient broth was each transferred into test tube. Later, the extract was serially diluted to the concentration of 250,200,150, 100 and $50 \mu \mathrm{g} / \mathrm{mL}$. Then, $0.5 \mathrm{~mL}$ organism was aspirated and transferred the test tubes containing both the broth and the extract which was incubated at $37^{\circ} \mathrm{C}$ for 24 hours. The MIC was observed as the lowest concentration of the leaf extract with no visible growth of the test organism.

Experimental animals

Adult male albino rats weighing 184-192 g were sourced from the Department of Pharmacology, University of Calabar and used for the experiments. All animals were housed in plastic cages with wire gauzed tops and saw dust as beddings. They were acclimatized for seven days in laboratory conditions (relative humidity of $50 \pm 5 \%$, temperature $28 \pm 2^{\circ} \mathrm{C}$ and 12 hours of light/ dark cycle) and maintained on the same conditions for the duration of the studies. The rats were fed with pellets (Agro Feeds, Calabar) and clean water ad libitum. Handling of the animals was according to the International Guidelines for Care and handling of experimental animals (12).

Toxicological evaluation

Acute toxicity test

Male Albino rats weighing 184-192 g grouped in 4 per cage were orally treated with the test leaf extract $(A$. macrophylla) at doses of $100 \mathrm{mg} / \mathrm{kg}, 600 \mathrm{mg} / \mathrm{kg}, 1000 \mathrm{mg} /$ $\mathrm{kg}, 2000 \mathrm{mg} / \mathrm{kg}, 3000 \mathrm{mg} / \mathrm{kg}$ and $5000 \mathrm{mg} / \mathrm{kg}$ (4 rats for each dose). Each group of rats was placed in a test cage for 
a 45-minute adaptation period before oral administration of the extract using an orogastric cannula. The animals were first observed for 4 hours and later 72 hours. Toxicity signs and mortality were recorded for each group after the observation period (13). The experimental rats were monitored further for seven days.

Sub-acute toxicity study

The protocol described in Organization Economic Community Development (OECD) guidelines number 407 (14) was adopted but with slight modifications. Twenty-four male albino rats weighed and grouped into 4 with $6(n=6)$ rats in each group were used for the study. The treatment groups were administered daily via a gastric cannula - $100 \mathrm{mg} / \mathrm{kg}, 200 \mathrm{mg} / \mathrm{kg}$ and $400 \mathrm{mg} / \mathrm{kg}$ body weight of the ethanol leaf extract of $A$. macrophylla respectively, while control rats were given distilled water for 28 days. At the end of experimentation, the rats were anesthetized under chloroform vapour and blood samples collected via cardiac puncture into plain and EDTA containing sample bottles for biochemical and hematological analyses respectively. The organs (liver, kidney, heart and lungs) were removed, weighed and examined microscopically.

\section{Hematologic analysis}

Hematological analysis was done with an automated hematology analyzer (Sysmex-XT-1800, Kobe, Japan) in the University of Calabar Teaching Hospital, Calabar, Cross River State, Nigeria.

\section{Biochemical studies}

Serum was generated by allowing the blood in the plain bottles to stand for 3 hours at room temperature to ensure complete clotting; centrifuging the clotted samples at 3500 rpm for 10 minutes and the resultant clear serum was aspirated and stored for the biochemical studies.

Biochemical indices were determined with standard ready-to-use reagent kits (Randox Ltd, UK) following the manufacturer's instructions. The indices assessed were liver indices (aspartate aminotransferase - AST, alanine aminotransferase - ALT, alkaline phosphatase - ALP, total proteins/albumin levels and bilirubin levels - total/direct/ indirect), kidney indices (electrolytes, creatinine and uric acid.

\section{Organ weights}

The rats' vital organs (heart, lungs, liver and kidneys) were excised, cleaned of blood, weighed and examined macroscopically, and their relative weights calculated as: Relative organ weight - ROW (\%) = weight of organ / body weight of rat $\times 100$.

\section{Statistical Analysis}

The SPSS version 20.0 software was used for data processing and values obtained from descriptive statistics expressed as means \pm SEM. Statistical significance was determined with one-way analysis of variance (ANOVA) followed by Tukey's post hoc multiple comparison tests. Differences were considered significant at $P<0.05$.

\section{Results}

Phytochemical constituents

Phytochemicals detected in the ethanol leaf extract of A. macrophylla were polyphenols, tannins, flavonoids, saponins, steroids, glycosides, alkaloids, while anthraquinones were absent.

\section{Antibacterial activity}

The results of antibacterial activity of the ethanol leaf extract and the MIC for the organisms are presented in Table 1 . The leaf extract showed greater activity against $E$. coli, K. pneumonia, S. pyogenes and $S$ aureus. Cefoxitin at concentration of $20 \mu \mathrm{g} / \mathrm{mL}$, showed activity against all the tested pathogenic bacteria.

\section{Acute toxicity test}

The ethanol leaf extract of $A$. macrophylla did not produce any lethality or visible signs of toxicity in rats up to the oral dose level of $5000 \mathrm{mg} / \mathrm{kg}$ body weight 24 hours after treatment. Further monitoring for seven days did not still yield mortality or visible toxic signs. Hence, the $\mathrm{LD}_{50}$ value was greater than $5000 \mathrm{mg} / \mathrm{kg}$ body weight.

\section{Effects on hematological indices}

Table 2 represents the effects of ethanol leaf extract of A. macrophylla on hematological indices. There were insignificant alterations in hematological parameters in rats exposed to all doses of the ethanol leaf extract compared to control.

\section{Effects on biochemical parameters}

The effects of A. macrophylla ethanol leaf extract assessment on biochemical parameters in rats are shown in Table 3. The extract produced non-significant effects on the plasma levels of liver enzymes (ALT, AST and ALP), total proteins and albumin compared to the control group.

Table 1. Antibacterial activity of the ethanol leaf extract and the MIC

\begin{tabular}{lccc}
\hline \multirow{2}{*}{ Organisms } & \multicolumn{2}{c}{$\begin{array}{c}\text { Inhibition zones of } \\
\text { bacteria }(\mathrm{mm})\end{array}$} & MIC $(\mu \mathrm{g} / \mathrm{mL})$ \\
\cline { 2 - 3 } & Extract & Cefoxitin & \\
\hline Staphylococcus aureus & 11 & 12 & 23 \\
Escherichia coli & 20 & 9 & 25 \\
Salmonella typhi & 8 & 8 & 100 \\
Klebsiella pneumonia & 16 & 8 & 12.5 \\
Streptococcus pyogenes & 14 & 10 & 27 \\
Bacillus subtilis & 10 & 10 & 25 \\
\hline
\end{tabular}

MIC, Minimum inhibitory concentration. 
Table 2. Effects of ethanol leaf extract of Anthonotha macrophylla on rats' hematological indices

\begin{tabular}{|c|c|c|c|c|}
\hline \multirow{2}{*}{ Parameters } & \multirow{2}{*}{ Control } & \multicolumn{3}{|c|}{ Doses } \\
\hline & & 100 & 200 & 400 \\
\hline $\mathrm{RBC}\left(\mathrm{x} 10^{12} / \mathrm{L}\right)$ & $8.82 \pm 2.17$ & $8.62 \pm 2.55$ & $9.11 \pm 1.71$ & $8.80 \pm 2.52$ \\
\hline HGB (g/dL) & $16.90 \pm 2.20$ & $16.62 \pm 2.81$ & $17.19 \pm 1.91$ & $17.51 \pm 2.16$ \\
\hline PCV (\%) & $51.51 \pm 0.31$ & $50.18 \pm 0.11$ & $52.20 \pm 0.22$ & $52.80 \pm 0.03$ \\
\hline MCV (fl) & $32.16 \pm 0.33$ & $31.91 \pm 0.25$ & $32.06 \pm 0.19$ & $31.84 \pm 0.54$ \\
\hline $\mathrm{MCHC}(\mathrm{g} / \mathrm{dL})$ & $31.29 \pm 0.51$ & $30.94 \pm 0.88$ & $30.60 \pm 0.59$ & $31.23 \pm 0.22$ \\
\hline WBC $\left(\times 10^{9} / L\right)$ & $11.43 \pm 0.75$ & $11.61 \pm 0.51$ & $11.42 \pm 0.94$ & $11.72 \pm 0.66$ \\
\hline $\operatorname{PLT}\left(10^{3} / \mathrm{L}\right)$ & $945.11 \pm 42.81$ & $944.00 \pm 44.1$ & $943.93 \pm 50.81$ & $950.03 \pm 50.11$ \\
\hline Neutrophils (\%) & $25.03 \pm 1.61$ & $25.11 \pm 1.33$ & $24.76 \pm 2.01$ & $25.56 \pm 1.11$ \\
\hline Lymphocytes (\%) & $70.54 \pm 11.10$ & $70.33 \pm 11.06$ & $70.59 \pm 10.9$ & $70.31 \pm 12.21$ \\
\hline Monocytes (\%) & $1.06 \pm 0.32$ & $0.91 \pm 0.42$ & $1.05 \pm 0.29$ & $0.94 \pm 0.42$ \\
\hline Eosinophil (\%) & $1.23 \pm 0.16$ & $1.31 \pm 0.11$ & $1.22 \pm 0.14$ & $1.30 \pm 0.12$ \\
\hline
\end{tabular}

Values are means $\pm \operatorname{SEM}(n=6)$.

$\mathrm{RBC}$, red blood cells; $\mathrm{HGB}$, hemoglobin; PCV, packed cell volume; MCV, mean corpuscular volume; MCHC, mean corpuscular hemoglobin concentration; WBC, white blood cells; PLT, platelets.

Table 3. Effect of ethanol leaf extract of Anthonotha macrophylla on rats' liver indices

\begin{tabular}{lccc}
\hline \multirow{2}{*}{ Parameters } & Control & $\mathbf{1 0 0}$ & \multicolumn{2}{c}{ Doses } \\
\cline { 3 - 4 } & & 1700 & $\mathbf{2 0 0}$ \\
AST (IU/L) & $170.1 \pm 14.2$ & $173.4 \pm 13.2$ & $175.0 \pm 6.2$ \\
ALT (IU/L) & $46.5 \pm 9.5$ & $47.9 \pm 10.7$ & $48.4 \pm 6.4$ \\
ALP (IU/L) & $196.71 \pm 10.1$ & $198.4 \pm 10.1$ & $196.4 \pm 11.3$ \\
TP (g/dL) & $6.65 \pm 3.2$ & $6.01 \pm 4.4$ & $6.61 \pm 3.5$ \\
Alb. (g/dL) & $2.75 \pm 11.1$ & $2.70 \pm 9.2$ & $2.67 \pm 8.5$ \\
\hline
\end{tabular}

Values are means $\pm \operatorname{SEM}(n=6)$.

AST, Aspartate aminotransferase, ALT, alanine aminotransferase; ALP, alkaline phosphatase; TP, total protein; Alb, albumin.

Effects on lipid profile

As shown in Table 4, the lipid profile of treated rats was not significantly altered in the ethanol leaf extract treated rats compared to the control group.

Effects on renal indices

Analysis of renal parameters in the extract treated rats showed a non-significant reduction in concentration at all employed doses compared to control group (Table 5).

Effects on relative organ weight of rats

There was no significant difference in the rats' relative vital organs weights in the extract-treated rats compared with the control group (Table 6).

\section{Discussion}

Herbal medications are globally gaining popularity in primary health care with great potential to provide new therapeutic agents. However, there are concerns about the scarcity of scientific information on safety profiles of most of these products (15). The pharmacological actions, beneficial and adverse effects of herbal recipes are attributed to their chemical constituents (16). Different methods are available for obtaining the constituents

Table 4. Effect of leaf extract of Anthonotha macrophylla on lipid profile of rats

\begin{tabular}{llcr}
\hline \multirow{2}{*}{ Parameters } & Control & \multicolumn{2}{c}{ Doses } \\
\cline { 3 - 4 } & & $\mathbf{1 0 0}$ & $\mathbf{2 0 0}$ \\
\hline Triglycerides (mmol/L) & $0.67 \pm 0.15$ & $0.69 \pm 0.12$ & $0.73 \pm 0.08$ \\
Total cholesterol (mmol/L) & $1.74 \pm 5.11$ & $1.72 \pm 7.10$ & $1.77 \pm 9.01$ \\
HDL (mmol/L) & $0.33 \pm 0.71$ & $0.31 \pm 0.10$ & $0.34 \pm 0.05$ \\
LDL (mmol/L) & $1.11 \pm 0.11$ & $1.13 \pm 0.12$ & $1.12 \pm 0.04$ \\
VLDL (mmol/L) & $0.30 \pm 0.05$ & $0.28 \pm 0.06$ & 0.14 \\
\hline
\end{tabular}

Values are means \pm SEM $(n=6)$.

HDL, high density lipoprotein; LDL, low density lipoproteins; VLDL, very low density lipoprotein. 
Table 5. Effect of ethanol leaf extract of Anthonotha macrophylla on rats' kidney indices

\begin{tabular}{|c|c|c|c|c|}
\hline \multirow{2}{*}{ Parameters } & \multirow{2}{*}{ Control } & \multicolumn{3}{|c|}{ Doses } \\
\hline & & 100 & 200 & 400 \\
\hline $\mathrm{Na}(\mathrm{mmol} / \mathrm{L})$ & $141.6 \pm 10.3$ & $140.9 \pm 11.2$ & $142.4 \pm 10.6$ & $142.3 \pm 15.2$ \\
\hline $\mathrm{Ca}(\mathrm{mmol} / \mathrm{L})$ & $2.7 \pm 0.3$ & $2.6 \pm 0.4$ & $2.7 \pm 0.3$ & $2.5 \pm 0.7$ \\
\hline $\mathrm{K}(\mathrm{mmol} / \mathrm{L})$ & $5.5 \pm 1.2$ & $5.4 \pm 1.7$ & $5.8 \pm 0.6$ & $5.9 \pm 1.0$ \\
\hline $\mathrm{Cl}(\mathrm{mmol} / \mathrm{L})$ & $96.4 \pm 6.3$ & $93.6 \pm 7.1$ & $97.0 \pm 5.8$ & $96.3 \pm 6.8$ \\
\hline Phosphate (mmol/L) & $2.0 \pm 0.3$ & $2.0 \pm 0.5$ & $2.1 \pm 0.3$ & $2.3 \pm 0.1$ \\
\hline Creatinine $(\mu \mathrm{mol} / \mathrm{L})$ & $42.6 \pm 2.1$ & $43.3 \pm 1.8$ & $41.6 \pm 6.3$ & $43.6 \pm 4.0$ \\
\hline Urea (mmol/L) & $8.3 \pm 1.0$ & $8.2 \pm 1.5$ & $8.0 \pm 2.5$ & $8.4 \pm 1.0$ \\
\hline Uric acid (mmol/L) & $159.3 \pm 11.7$ & $160.8 \pm 10.6$ & $161.4 \pm 9.5$ & $159.9 \pm 16.8$ \\
\hline
\end{tabular}

Values are means \pm SEM $(n=6)$.

Table 6. Effect of leaf extract of Anthonotha macrophylla on albino rats' relative weight of vital organs weight

\begin{tabular}{lccr}
\hline Parameters & Control & \multicolumn{2}{c}{ Doses } \\
\cline { 3 - 4 } Liver & & $\mathbf{1 0 0}$ & $\mathbf{2 0 0}$ \\
Kidney & $3.51 \pm 0.13$ & $3.50 \pm 0.10$ & $3.49 \pm 0.25$ \\
Heart & $0.76 \pm 0.02$ & $0.75 \pm 0.05$ & $0.77 \pm 0.04$ \\
Lungs & $0.38 \pm 0.01$ & $0.39 \pm 0.01$ & $0.40 \pm 0.01$ \\
\hline
\end{tabular}

Values are means \pm SEM $(n=6)$.

of any medicinal plants. Phytochemical analysis of the ethanol leaf extract of A. macrophylla revealed the presence in varied proportions of alkaloids, saponins, tannins, polyphenols, flavonoids, steroids, glycosides and anthraquinones. Initial screening of medicinal plants for secondary metabolites assists the detection of bioactive compounds, which may initiate drug discovery in one hand and possible adverse effects on the other hand (17). These biochemicals may be behind the observed effects in this study.

Antimicrobial properties of medicinal plants are being increasingly reported globally. In this study, the leaf extract exhibited potent activity against the tested pathogenic bacteria suggesting that it contains bioactive compounds that can serve as antibacterial agent(s) or lead compound for the synthesis of such agent(s). Although the antibacterial property of the leaf extract is related to its phytoconstituents especially alkaloids and also others, some alkaloids specifically those belonging to betacarboline group possess antimicrobial, anti-HIV and antiparasitic activities (18). The potency of $A$. macrophylla against tested bacteria gives a piece of evidence for the medicinal value and provides the basis for its traditional usage as a remedy for skin infections like boils.

Acute toxicity study enables the researcher to determine the nature and degree of toxic reactions that may follow a single, usually large dose exposure to an agent, as may occur clinically in overdose. In this study, there was no evidence of toxicity in rats exposed singly to different doses of the leaf extract even when a dose of $5000 \mathrm{mg} /$ $\mathrm{kg}$ body weight was used. Hence the ethanol leaf extract can be considered as being non-toxic following acute administration. This observation of a good safety profile may explain why the plant's leaf is widely used in folkloric medicine.

Sub-acute toxicity studies on the other hand help identify any organ targeted toxic effects. The tests also help one to know the extent of non-observable adverse effect (19) as well as appropriate dose regimens for long-term studies. Alterations in body and organ weights of animals exposed to xenobiotics are accepted indicators of changes induced by the agents (20). In toxicological evaluation, the weights of vital organs are sensitive indicator of the effects of a xenobiotic for it defines toxicity as significant changes are shown in those organs (21). In this work, there was insignificant changes in the relative vital organs and lack of gross abnormalities signifying that the extract did not alter normal growth.

Hematopoiesis, a process that is vital to life can be affected by both conventional and herbal medications. Evaluation of hematological indices in animal models provides information on blood related benefits of plant extracts and also their toxic manifestations (22). Furthermore, the analysis is useful in risk assessment in humans as data from hematological changes in animals when translated have a marked predictive value for human toxicity. The results of hematological assessment in this study did not show any significant changes in hematological indices. The erythrocyte indices being a part of the above mentioned was not affected. It can be said that the leaf extract did not affect erythropoiesis, morphology or osmotic fragility of the red blood cells (23). The lack of significant alterations extended to the total white blood cells and its differentials. Since these cells are the major 
effectors of both innate and adaptive immunities (24), it can be interpreted that the leaf extract has no effect on immune responses. Platelets counts were also not altered in this study, implying that the leaf extract has no effect on hemostasis, which is being controlled by platelets. The lack of alterations in hematopoietic indices may be a sign that the extract does not affect the bone marrow adversely since all the blood cells originate from the hematopoietic stem cells in the bone marrow (25). On the other hand, the observed effects may occur because the extract did not alter the main stimulants in the pathway namely, erythropoietin for erythropoiesis and thrombopoietin for thrombocytosis. All observations point to the nonhematotoxic nature of the extract at the doses used in this study. Other researchers working on varied plant extracts also recorded similar effects $(26,27,28,29)$. However, since changes in hematological parameters occur relatively slowly, the experimental duration may not have been enough to identify any alterations, and such was the findings with Lychnophora trichocarpha (30). Even though some of the phytochemicals found in the extract have established stimulant effect on hematopoiesis, the doses used may have been too small to allow such effects.

The serum chemistry evaluation was to assess the effect of the extract on hepatic and renal functions of treated rats compared to controls. The liver and kidney are important elimination and synthetic organs and analysis of their functions is extremely essential in toxic evaluation of xenobiotics (31). The ethanol leaf extract of A. macrophylla did not significantly alter any of the liver and kidney parameters assessed. A rise in serum levels of AST, ALT and ALP serve as an indicator of hepatotoxicity or liver diseases (32). Because serum proteins especially albumin are synthesized within the hepatocytes, their levels are used to assess liver's synthetic capacity (33). The absence of significant alterations of liver indices in extract-treated rats compared to control in this study suggests that the extract did not affect the hepatocytes. Many markers are used to evaluate kidney functions including serum creatinine which is the most sensitive and serum potassium, the most convincing electrolyte marker $(34,35)$. In this study, none of these markers was altered signifying that the extract is not nephrotoxic. Equally, there were no changes in the lipid profile of extract- treated rats compared to control. This implies that the extract did not affect the processes that may lead to increase levels of plasma lipoproteins especially low-density lipoproteins (LDL), which include hepatic cholesterol biosynthesis, increased fecal bile acid secretion and stimulation of receptor-mediated catabolism of LDL-cholesterol and uptake of LDL from blood in the liver (36).

\section{Conclusion}

The observations in this study suggest that the ethanol leaf extract of A. macrophylla has a broad spectrum of antibacterial activities that can be exploited in the management of human infections due to the investigated bacteria. Findings also indicate that oral administration of the ethanol leaf extract is relatively safe as reflected in the results of acute and sub-acute studies. The observed antimicrobial potential and nontoxic effects of $A$. macrophylla ethanol leaf extract make it a candidate for bioassay guided and isolation of compounds which can possibly be developed into new lead structures for drug development programs against diseases.

\section{Authors' contributions}

GAE conceived the research idea. MUA designed the work. GCA wrote the first draft of the manuscript. GAA and AUM carried out the literature search. ADOJ and CCO carried out the statistical analysis. All authors read and approved the final manuscript.

\section{Conflict of interests}

The authors declare no conflict of interests.

\section{Ethical considerations}

The protocol for this study was confirmed by ethical committee (UNICAL/010/PA/2016) and the authors of this manuscript observed ethical issues. Animals were handled according to the International Guidelines for Care and Handling of Experimental Animals.

\section{Funding/Support}

This research was financially supported by the authors.

\section{References}

1. Farnsworth NR, Akerele O, Bingel AS, Soejarto DD, Guo Z. Medicinal plants in therapy. Bull World Health Organ. 1985;63(6):965-81.

2. Klayman DL. Artemisia annua: from weed to respectable antimalarial plant. In: Kinghorn AD, Belandrin MF, eds. Human Medicinal Agents from Plants. American Chemical Society; 1993. p. 242-55.

3. Fabricant DS, Farnsworth NR. The value of plants used in traditional medicine for drug discovery. Environ Health Perspect. 2001;109 Suppl 1:69-75. doi: 10.1289/ ehp.01109s169.

4. Bodeker C, Bodeker G, Ong CK, Grundy C, Burford G, Shein K. WHO global atlas of traditional, complementary and alternative medicine. Geneva: World Health Organization; 2005.

5. Abere TA, Okoto PE, Agoreyo FO. Antidiarrhoea and toxicological evaluation of the leaf extract of Dissotis rotundifolia Triana (Melastomataceae). BMC Complement Altern Med. 2010;10:71. doi: 10.1186/1472-6882-10-71.

6. Lawal IO, Uzokwe NE, Igboanugo ABI, Adio AF, Awosan EA, Nwogwugwu JO, et al. Ethno medicinal information on collation and identification of some medicinal plants in Research Institutes of South-west Nigeria. Afr J Pharm Pharmacol. 2010;4(1):1-7.

7. Zirihi Guede N, N'guessan KT, Etien Dibie T, Grellier P. 
Ethnopharmacological study of plants used to treat malaria, in traditional medicine. J Pharm Sci Res. 2010;2(4):216-27.

8. Oloyede OI. Chemical profile of unripe pulp of Carica papaya. Pak J Nutr. 2005;4(6):379-81.

9. Ajayi AO. Antimicrobial nature and use of some medicinal plants in Nigeria. Afr J Biotechnol. 2008;7(5):595-9.

10. Akuodor GC, Onyewenjo SC, Anyalewechi NA, Essien $\mathrm{AD}$, Akpan JL, Okoroafor DO, et al. In vitro antimicrobial activity of leaf extract of Berlina grandiflora Hutch. and Dalz. Afr J Microbiol Res. 2011;5(11):1358-60. doi: 10.5897/ AJMR10.692.

11. Andrews JM. Determination of minimum inhibitory concentrations. J Antimicrob Chemother. 2001;48 Suppl $1: 5-16$.

12. National Institutes of Health (NIH). Guide for the care and use of laboratory animals. 8th ed. Bethesda, MD: NIH; 2006:82-3.

13. Organisation for Economic Cooperation and Development. Guidelines for the Testing of Chemicals/Section 4: Health Effects Test No. 423, Acute oral toxicity-acute toxic class method. Paris: OECD; 2002.

14. Organisation for Economic Cooperation and Development. OECD Guideline for Testing of Chemicals (TG 407). Repeated Dose 28-Day Oral Toxicity Study in Rodents. OECD; 2008.

15. Sood R. Textbook of Laboratory Technology. New Delhi: Jaypee Bothers Medical Publishing Ltd; 2006. p. 598-690.

16. Wang L, Li Z, Li L, Li Y, Yu M, Zhou Y, et al. Acute and sub-chronic oral toxicity profiles of the aqueous extract of Cortex Dictamni in mice and rats. J Ethnopharmacol. 2014;158 Pt A:207-15. doi: 10.1016/j.jep.2014.10.027.

17. Aziz MA. Qualitative phytochemical screening and evaluation of anti-inflammatory, analgesic and antipyretic activities of Microcos paniculata barks and fruits. J Integr Med. 2015;13(3):173-84. doi: 10.1016/s20954964(15)60179-0.

18. Patel K, Gadewar M, Tripathi R, Prasad SK, Patel DK. A review on medicinal importance, pharmacological activity and bioanalytical aspects of beta-carboline alkaloid "Harmine". Asian Pac J Trop Biomed. 2012;2(8):660-4. doi: 10.1016/s2221-1691(12)60116-6.

19. National Research Council. National Research Council recommended daily dietary Allowance. USA Nutri Rev. 2006;31(12):374-90.

20. Sellers RS, Morton D, Michael B, Roome N, Johnson JK, Yano BL, et al. Society of Toxicologic Pathology position paper: organ weight recommendations for toxicology studies. Toxicol Pathol. 2007;35(5):751-5. doi: 10.1080/01926230701595300.

21. Teo S, Stirling D, Thomas S, Hoberman A, Kiorpes A, Khetani V. A 90-day oral gavage toxicity study of D-methylphenidate and D, L-methylphenidate in SpragueDawley rats. Toxicology. 2002;179(3):183-96

22. Yakubu MT, Akanji MA, Oladiji AT. Hematological evaluation in male albino rats following chronic administration of aqueous extract of Fadogia agrestis stem. Pharmacog Mag. 2007;3(9):34-8.

23. Guyton AC, Hall JE. Textbook of Medical Physiology. Philadelphia, PA, USA: WB Saunders; 2000. p. 1152.

24. Kaur S, Khan S, Nigam A. Hematological profile and pregnancy: a review. Int J Adv Med. 2014;1(2):68-70. doi: 10.5455/2349-3933.ijam20140804.

25. Lemischka IR, Raulet DH, Mulligan RC. Developmental potential and dynamic behavior of hematopoietic stem cells. Cell. 1986; 45:917-92.

26. Oduola T, Adeniyi FAA, Ogunyemi EO, Bello IS, Idowu TO, Subair HG. Toxicity studies on an unripe Carica papaya aqueous extract: biochemical and haematological effects in waster albino rats. J Med Plant Res. 2007;1(1):1-4.

27. Devaki K, Beulah U, Akila G, Gopalakrishnan VK. Effect of aqueous extract of Passiflora edulis on biochemical and hematological parameters of Wistar albino rats. Toxicol Int. 2012;19(1):63-7. doi: 10.4103/0971-6580.94508.

28. Ferreira SA, Guimaraes AG, Ferrari FC, Carneiro CM, de Paiva NC, Guimaraes DAS. Assessment of acute toxicity of the ethanolic extract of Lychnophora pinaster (Brazilian arnica). Rev Bras Farmacogn. 2014;24(5):553-60. doi: 10.1016/j.bjp.2014.09.005.

29. Essiet GA, Takem LP, Essien AD, Akuodor GC, Udoh FV. Assessment of haematopoietic toxicity of Salacia lehmbachii. Int J Pharm Pharm Res. 2016;8(1):326-32.

30. Ferrari FC, Grabe-Guimaraes A, Carneiro CM, de Souza MR, Ferreira LC, de Oliveira TT, et al. Toxicological evaluation of ethanolic extract of Lychnophora trichocarpha, Brazilian arnica. Rev Bras Farmacogn. 2012;22(5):1104-10. doi: 10.1590/S0102-695X2012005000089.

31. Olorunnisola OS, Bradley G, Afolanya AJ. Acute and subchronic toxicity studies of methanolic extract of Tulbaghia violacea rhizomes in Wistar rats. Afr J Biotechnol. 2012;11(83):14934-40

32. Harris EH. Elevated liver function tests in type 2 diabetes. Clin Diabetes. 2005;23(3):115-9. doi: 10.2337/ diaclin.23.3.115.

33. Rasekh HR, Nazari P, Kamli-Nejad M, Hosseinzadeh L Acute and subchronic oral toxicity of Galega officinalis in rats. J Ethnopharmacol. 2008;116(1):21-6. doi: 10.1016/j. jep.2007.10.030.

34. Saad B, Azaizeh H, Abu-Hijleh G, Said O. Safety of traditional Arab herbal medicine. Evid Based Complement Alternat Med. 2006;3(4):433-9. doi: 10.1093/ecam/nel058.

35. Gowda S, Desai PB, Kulkarni SS, Hull VV, Math AA, Vernekar SN. Markers of renal function tests. N Am J Med Sci. 2010;2(4):170-3.

36. Khanna AK, Chander R, Kapoor NK. Terminalia arjuna: an ayurvedic cardiotonic, regulates lipid metabolism in hyperlipaemic rats. Phytother Res. 1996;10(8):6635. doi: 10.1002/(sici)1099-1573(199612)10:8<663::aidptr935>3.0.co;2-w. 